\title{
Reversible airway obstruction caused by changing the size and length of an endotracheal tube in a premature neonate with suspected tracheomalacia
}

\section{-A case report-}

\author{
Young Suk Kwon, Yun Hee Lim, Hae Lang Park, Byung Hoon Yoo, Seung Hoon Woo, and Jun Heum Yon \\ Department of Anesthesiology and Pain Medicine, Sanggye Paik Hospital, College of Medicine, Inje University, Seoul, Korea
}

Tracheomalacia is a malformation of the tracheal membranosa. It is maintained during spontaneous breathing but can be altered by bronchoscopy or positive airway pressure. Tracheomalacia is associated with a high mortality and may cause prolonged intubation and ventilation. Here, the case of a 13-day-old infant with jejunoileal stenosis that had surgery is reported. During induction of general anesthesia, endotracheal intubation was attempted several times with different sized endotracheal tubes. Airway obstruction occurred after the endotracheal intubation. After the airway was maintained, the operation was completed. Tracheomalacia was diagnosed after otolaryngology evaluation postoperatively. (Korean J Anesthesiol 2010; 59: S30-S32)

Key Words: Airway obstruction, Prematurity, Tracheomalacia.

Tracheomalacia is a rare, serious malformation associated with a high mortality rate in the neonate [1], it can require prolonged mechanical ventilation with endotracheal intubation. Tracheomalacia is caused by abnormality of tracheal cartilage resulting in the weakening of the tracheal wall. The airway is maintained during spontaneous breathing. However, the airway may be transformed when the pressure of the trachea changes or by the passage of a bronchoscope [2]. Tracheomalacia can easily be affected by the aorta anteriorly and the esophagus posteriorly [3]. There are previous cases reported where $[4,5]$ in patients anesthesized after diagnosed with tracheomalacia. There is no report in which patients were suspected of having tracheomalacia during induction of anesthesia. Here, a newborn is reported with obstruction of the airway that was suspected to be due to tracheomalacia.

\section{Case Report}

The patient was a 13-day-old male infant 1,350 g at birth, who was born by cesarean delivery. Pulmonary surfactant was administered via an endotracheal tube twice because of respiratory distress syndrome and the newborn was provided with mechanical ventilation for 35 hours. The patient received oxygen by hood until the sixth day of life, and received $2.5 \mathrm{mg}$

Received: June 22, 2010. Revised: 1st, July 6, 2010; 2nd, July 27, 2010. Accepted: August 18, 2010.

Corresponding author: Yun Hee Lim, M.D., Department of Anesthesiology and Pain Medicine, Sanggye Paik Hospital, College of Medicine, Inje University, Sanggye 7-dong, Nowon-gu, Seoul 139-707, Korea. Tel: 82-2-950-1173, Fax: 82-2-950-1323, E-mail: painfree@paik.ac.kr (c) This is an open-access article distributed under the terms of the Creative Commons Attribution Non-Commercial License (http:// creativecommons.org/licenses/by-nc/3.0/), which permits unrestricted non-commercial use, distribution, and reproduction in any medium, provided the original work is properly cited. 
injections of aminophylline every 12 hours because of apnea diagnosed on the eighth day of life. Surgery was planned due to jejunoileal obstruction, diagnosed by a gastrograffin enema. Gavage feeding was discontinued and bile excretion was noted.

Before the surgery, the vital signs were stable. There were no abnormalities on the ECG or chest X-ray. On the day of surgery, the weight was $1,390 \mathrm{~g}$ and there was no premedication before the anesthesia. Standard monitoring (electrocardiogram, noninvasive blood pressure and peripheral pulse oxygen saturation) was performed. Injection of $500 \mathrm{ml}$ of $10 \%$ dextrose water $+\mathrm{NaCl} 15 \mathrm{mEq}+$ heparin $500 \mathrm{IU} 8 \mathrm{ml} / \mathrm{hr}$ was carried out via the internal jugular vein using a 24 gauge catheter and was maintained at $10-0 \mathrm{ml} / \mathrm{hr}$ during the surgery. An 8 vol\% of sevoflurane was administered and then maintained with a 3 vol\% of sevoflurane. Fresh gas flow was maintained with $\mathrm{O}_{2} 1 \mathrm{~L} / \mathrm{min}$ and air $4 \mathrm{~L} / \mathrm{min}$. Injection of $1 \mathrm{mg}$ of rocuronium was administered because there was no difficulty with mask ventilation.

Two minutes later, intubation with a $2.0 \mathrm{~mm}$ ID (internal diameter) endotracheal tube was attempted. After the endotracheal intubation, the patient could not be ventilated. The $\mathrm{EtCO}_{2}$ was measured at $0 \mathrm{mmHg}$. Therefore, the endotracheal tube was removed and mask ventilation was provided. The tube was checked and intubation attempted again with the same endotracheal tube, two minutes later. However, the second attempt failed and mask ventilation was again provided. Endotracheal intubation was attempted by a different anesthesiologist, however, all attempts failed.

Tracheal intubation with a $2.5 \mathrm{~mm}$ ID endotracheal tube was attempted. After the intubation, ventilation was successful and breath sounds present bilaterally. The tube was fixed at $7 \mathrm{~cm}$ the tube was cut from $12 \mathrm{~cm}$ to reduce the dead space. After cutting the tube, ventilation failed and the $\mathrm{EtCO}_{2}$ was $0 \mathrm{mmHg}$. There was no change in the depth; ventilation could not be provided and there were no breath sounds. The endotracheal tube was removed and mask ventilation was provided again. Intubation with the same endotracheal tube after two minutes was tried again. The ventilation was successful and breathing sounds could be heard in the lungs bilaterally. The tube was fixed at 7 $\mathrm{cm}$ and cut from $12 \mathrm{~cm}$ to reduce the dead space. After cutting the tube, ventilation failed and the $\mathrm{EtCO}_{2}$ was $0 \mathrm{mmHg}$ again. One-lung ventilation was suspected, so manual ventilation was attempted, changing the depth of the endotracheal tube.

Intubation with a $3.0 \mathrm{~mm}$ ID endotracheal tube was attempted. After the intubation, ventilation was successful and breath sounds were detected bilaterally, in addition, to regular capnography of the $\mathrm{EtCO}_{2}$. The tube was fixed at $7 \mathrm{~cm}$ and cut from 12 $\mathrm{cm}$ to reduce the dead space. However, this time the ventilation was successful. Manual ventilation was maintained without any additional problems. Twenty minutes before the end of surgery, spontaneous ventilation was encouraged. Injections with $0.05 \mathrm{mg}$ of pyridostigmine and $0.01 \mathrm{mg}$ of glycopyrrolate were provided and spontaneous ventilation occurred. After surgery, the patient was transferred to the ICU for potential apnea and mechanical ventilator care. The duration for anesthesia was $2 \mathrm{hr} 30 \mathrm{~min}$ and the operation was $2 \mathrm{hr}$. There was no specific change in the $\mathrm{BP}$ or $\mathrm{HR}$. The $\mathrm{SpO}_{2}$ was maintained at $95 \%$. Two hours after surgery, the endotracheal tube was removed because the respirations were stable. Fifteen days later, an otorhinolaryngologist diagnosed tracheomalacia by laryngoscope examination. However, rigid bronchoscopy was not performed for confirmation, because there were no specific symptoms at that time. The patient recovered without any respiratory problems.

\section{Discussion}

Cough, inspiratory stridor, and recurrent pneumonia are symptoms associated with tracheomalacia; the most severe symptom is apnea. In most cases, symptoms improve spontaneously and patients require conservative care. However, if severe apnea develops, recurrent pneumonia, or extubation failure, surgery is needed. Chest x-rays and bronchoscopy are used for the diagnosis. Tracheal narrowing is noted with expiration. On barium esophagography the trachea can be easily flattened by the esophagus [3].

Tracheomalacia is frequently associated with other congenital anomalies such as an esophageal stricture or tracheoesophageal fistula. It is also associated with tumors that can press on the trachea, connective tissue disorders and long-term high pressure ventilator care [6]. Common symptoms associated with a tracheoesophageal fistula include dyspnea during feeding, cyanosis, and aspiration pneumonia caused by regurgitation of food or saliva; this can be diagnosed by failure of attempts to insert a nasogastric tube. The diagnosis is usually made immediately after birth or within 15 days of life [7]. The H-type of tracheoesophageal fistula, which is not associated with an esophageal stricture, may have no specific symptoms until adulthood [8]. A tracheoesophageal fistula should be suspected when ventilation is not successful after endotracheal intubation. However, in this case, a tracheoesophageal fistula was ruled out because the patient had gavage tube feeding and there were no specific signs on the gastrograffin test.

Ventilation was not successful with a $2.0 \mathrm{~mm}$ ID tube or a cut $2.5 \mathrm{~mm}$ ID tube in this case. However, with a $3.0 \mathrm{~mm}$ ID tube, ventilation was successfully maintained. This is presumable explained by hydromechanics.

The relationship between the flow, the tube and gas in a straight tube is explained by the Hagen-Poiseuille equation [9]. The Hagen-Poiseuille equation is as follows: $\mathrm{V}=\pi \Delta \operatorname{Pr} 4 / 8 \mathrm{uL}(\mathrm{V}=$ 
flow and $\pi=3.1416, \mathrm{P}=$ pressures, $\mathrm{r}=$ radius of tube, $\mathrm{L}=$ length of tube, $\mathrm{u}=$ viscosity of gas). A tube with a smaller radius has greater flow; the flow was greatest for the $2.0 \mathrm{~mm}$ ID tube and slowest with the $3.0 \mathrm{~mm}$ ID tube. According to the Bernoulli effects, pressure decreases as the flow increases, at narrow points [9]. Turbulent flow occurs at the end of the tube where the radius of the tube changes. The relationship between the flow and the pressure is as follows: $\mathrm{V} \propto \Delta \mathrm{P}^{1 / 2}[9]$.

It is assumed that the obstruction of the airway was caused by the pressure outside of the tube. Flow increases with the 2.0 $\mathrm{mm}$ ID tube more than with $3.0 \mathrm{~mm}$ ID tube. The faster flow passes to the end of the tube and the pressure inside of the tube decreases when the faster flow passes the narrow point caused by the tracheomalacia. At that moment, obstruction of the airway occurs due to pressure outside of the tube.

In this case, ventilation was not successful immediately after the tube was cut to reduce the dead space when a $2.5 \mathrm{~mm}$ ID tube was used. This was likely caused by the Hagen-Poiseuille equation. Ventilation failure after cutting the tube was caused by obstruction of the airway due to a decrease in the pressure. The decrease in pressure was caused by shortening of the length of the tube which increases the flow rate; then, faster flow passes through the narrow segment.

Manczur et al. [10] reported that with a $4.0 \mathrm{~mm}$ ID tube, there is a $22 \%$ decrease in the resistance when the length of tube was changed to $11.3 \mathrm{~cm}$ from $20.7 \mathrm{~cm}$. The resistance is proportional to the pressure. The decrease of the pressure by $22 \%$ was associated with shortening of the length of the endotracheal tube. For endotracheal tubes smaller than the $4.0 \mathrm{~mm}$ ID tube, the decrease in the radius is associated with a rapid increase in the pressure. An increase in the gas flow from $5 \mathrm{~L} / \mathrm{min}$ to $10 \mathrm{~L} /$ min causes an increase of pressure from $81.2 \mathrm{H}_{2} \mathrm{O} / \mathrm{L} / \mathrm{sec}$ to 139.4 $\mathrm{H}_{2} \mathrm{O} / \mathrm{L} / \mathrm{sec}$ in a $2.5 \mathrm{~mm}$ ID tube while the pressure changes from $3.1 \mathrm{H}_{2} \mathrm{O} / \mathrm{L} / \mathrm{sec}$ to $4.6 \mathrm{H}_{2} \mathrm{O} / \mathrm{L} / \mathrm{sec}$ in a $6.0 \mathrm{~mm}$ ID tube [10].

In this case, the $2.5 \mathrm{~mm}$ ID tube length was changed from 18 $\mathrm{cm}$ to $12 \mathrm{~cm}$ and the $3.0 \mathrm{~mm}$ ID tube length was changed from $19 \mathrm{~cm}$ to $12 \mathrm{~cm}$. The flow in the tube was not laminar flow but turbulent flow, which is not directly proportional to the pressure or length. The decrease in pressure was $18 \%$ and $19 \%$, each, according to the relationship between the length of laminar flow and the pressure.

Disappearance of the parabola form, with turbulent flow, can lead to an increase in the pressure [9]. It is assumed that the decrease of pressure is lower with turbulent flow than with laminar flow. During manual ventilation, $5 \mathrm{~L} / \mathrm{min}$ was used; however, the fresh gas flow rate was briefly more than $10 \mathrm{~L} / \mathrm{min}$. It is assumed that the resistance increased rapidly in the smaller tube.

This patient received mechanical ventilator care and oxygen hood treatment before surgery; there were no abnormal symptoms associated with respiration. Blair et al. [11] reported that $95 \%$ of patients with tracheomalacia have no symptoms until two to three months after birth. Thus, when obstruction of the airway occurs during induction of general anesthesia, tracheomalacia should be suspected. It is important to select the radius and length of a tube carefully when endotracheal intubation is performed in a patient with tracheomalacia.

\section{References}

1. Austin J, Ali T. Tracheomalacia and bronchomalacia in children: pathophysiology, assessment, treatment and anaesthesia management. Paediatr Anaesth 2003; 13: 3-11.

2. Masters IB, Chang AB, Patterson L, Wainwright C, Buntain H, Dean BW, et al. Series of laryngomalacia, tracheomalacia, and bronchomalacia disorders and their associations with other conditions in children. Pediatr Pulmonol 2002; 34: 189-95.

3. Vinograd I, Klin B, Efrati Y, Barr J, Behar M, Eshel G. Airway obstruction in neonates and children: surgical treatment. J Cardiovasc Surg (Torino) 1994; 35: 7-12.

4. Shim KD, Lee JI, Chang CH, Nam YT. Anesthetic management of a child with tracheomalacia for aortopexy. Korean J Anesthesiol 2003; 45: 278-81

5. Olomu PN, Kidd JN, Koster KR. Use of the ProSeal laryngeal mask airway in an infant with a repaired $\mathrm{H}$-type tracheoesophageal fistula and tracheomalacia. Paediatr Anaesth 2008; 18: 74-6.

6. Messineo A, Filler RM. Tracheomalacia. Semin Pediatr Surg 1994; 3: 253-8.

7. Kirk KM, Dicks-Mireaux C. Difficulties in diagnosis of congenital H-type tracheo-oesophageal fistulae. Clin Radiol 1989; 40: 150-3.

8. Black RJ. Congenital tracheo-esophageal fistula in the adult. Thorax 1982; 37: 61-3.

9. Doyle DJ, O'Grady KF. Physics and modeling of the airway. In: Benumof's airway management. 2nd ed. Edited by Hagberg CA: Philadelphia, Mosby Elsevier. 2007, pp 86-114.

10. Manczur T, Greenough A, Nicholson GP, Rafferty GF. Resistance of pediatric and neonatal endotracheal tubes: influence of flow rate, size, and shape. Crit Care Med 2000; 28: 1595-8.

11. Blair GK, Cohen R, Filler RM. Treatment of tracheomalacia: eight years' experience. J Pediatr Surg 1986; 21: 781-5. 